conclusions regarding suicide among employed working populations. Last, the finding that suicide is highest among lower educated people in India may also mean a higher rate in lower skilled employed people, as education and occupational status are usually related.

1 Milner A, Spittal MJ, Pirkis J, LaMontagne AD. Suicide by occupation: systematic review and meta-analysis. Br J Psychiatry 2013; 203: 409-16.

2 Stansfeld SA, Pike C, McManus S, Harris J, Bebbington P, Brugha T, et al. Occupations, work characteristics and common mental disorder. Psychol Med 2013; 43: 961-73

3 LaMontagne AD, Keegel T, Louie AM, Ostry A. Job stress as a preventable upstream determinant of common mental disorders: a review for practitioners and policy-makers. Aust e-J Adv Ment Health 2010; 9: 17-35.

4 Ostry A, Maggi S, Tansey J, Dunn J, Hershler R, Chen L, et al. The impact of psychosocial work conditions on attempted and completed suicide among western Canadian sawmill workers. Scand J Public Health 2007; 35: 265-71.

5 Schneider B, Grebner K, Schnabel A, Hampel H, Georgi K, Seidler A. Impact of employment status and work-related factors on risk of completed suicide: a case-control psychological autopsy study. Psychiatry Res 2011; 190: 265-70.

Allison Milner, Research Fellow, McCaughey VicHealth Centre for Community Wellbeing, Melbourne School of Population and Global Health, University of Melbourne, Level 5, 207 Bouverie Street, Melbourne, VIC 3010, Australia. Email: allison.milner@unimelb.edu.au

doi: $10.1192 / \mathrm{bjp} .204 .5 .402 \mathrm{~b}$

\section{The rural employment advantage for people with psychosis: is it real?}

The population-based study on employment outcome for people with schizophrenia in rural $v$. urban China by Yang et $a l^{1}$ has revived the issue of rural advantage for people with psychoses in terms of functional outcome. However, I would like to point out a few methodological issues and practical considerations in the study that limit the interpretation of its results.

Non-inclusion of premorbid employment as a sociodemographic variable prevents us from gaining insight into the current employment status as a functional outcome marker. In addition, not incorporating elements of total work hours, income status and, most importantly, satisfaction with the current employment and simply considering the dichotomy of employed and unemployed with six subcategories seems too simplistic considering that employment outcome is the primary (and only) outcome that the study deals with. Inclusion of the category of underemployment (in addition to the categories of employed and unemployed), defined as employment not commensurate with one's educational level or premorbid occupational functioning, might have provided further valuable information regarding the employment outcome for these patients. ${ }^{2}$ Not including the type of psychotic illness in the regression model is a major drawback, given that some forms of psychotic illness included in the study (such as delusional disorder and brief psychotic disorder) typically are associated with better functional outcome than others (such as schizophrenia). ${ }^{3,4}$ Further, a basic question that has been left unaddressed in the discussion is whether the differences in rates of employment in patients in rural $v$. urban China is simply reflective of differences in the overall employment/unemployment rates for the general population in the rural and urban regions of the country. Reports have documented higher unemployment in the urban regions of China than in the rural regions. ${ }^{5}$ It would also be important to conceptualise the social integration or social inclusion that the authors have discussed as a composite of employment, community networking and a supportive social environment without undue emphasis only on employment measures. ${ }^{6}$ Last, but not least, the authors could have avoided using the term schizophrenia as a synonym for psychotic illnesses in the title of their paper, considering the spectrum of psychotic illnesses apart from schizophrenia that the study population covered. Notwithstanding the above methodological issues and practical considerations, I would like to congratulate the authors for undertaking a population-based study addressing the crucial issue of rural advantage in psychotic illnesses and the variables mediating the advantage, which has potential policy implications for this disadvantaged population.

1 Yang LH, Phillips MR, Li X, Yu G, Zhang J, Shi Q, et al. Employment outcome for people with schizophrenia in rural $v$. urban China: population-based study. Br J Psychiatry 2013; 203: 272-9.

2 International Labour Organization. Underemployment: current guidelines. ILO, 2013 (http://www.ilo.org/global/statistics-and-databases/statistics-overviewand-topics/underemployment/current-guidelines/lang-en/index.htm). Accessed 13 Dec 2013.

3 Jorgensen P. Course and outcome in delusional disorders. Psychopathology 1994; 27: 79-88.

4 Pillmann F, Wustmann T, Marneros A. Acute and transient psychotic disorders versus persistent delusional disorders: a comparative longitudinal study. Psychiatry Clin Neurosci 2012; 66: 44-52.

5 China Labour Bulletin. Employment in China. China Labour Bulletin 2013: Jun (http://www.clb.org.hk/en/content/employment-china). Accessed 13 Dec 2013.

6 Baumgartner JN, Susser E. Social integration in global mental health: what is it and how can it be measured? Epidemiol Psychiatr Sci 2013; 22: 29-37.

Sundar Gnanavel, Senior Resident, Department of Psychiatry, All India Institute of Medical Sciences, New Delhi, India. Email: sundar221103@yahoo.com

doi: 10.1192/bjp.204.5.403

Authors' reply: Dr Gnanavel's letter has raised several interesting methodological issues related to our paper. ${ }^{1} \mathrm{He}$ notes that employment is only one measure of social integration and social inclusion. We certainly agree that other measures of social integration beyond employment are needed. ${ }^{2}$ But fundamental differences in urban and rural environments make it extremely difficult to develop instruments that can validly assess social integration in both settings. Employment status is one of a very small set of variables about social functioning that can be readily measured and meaningfully compared (with the caveats noted below) between urban and rural settings. More detailed evaluation of community networking and social support may require the development of rural-specific and urban-specific measures; information from surveys that use these scales could then be used to devise and assess targeted interventions.

He also remarks on the need to consider work hours and work satisfaction when assessing the occupational functioning of persons with schizophrenia. We agree with the general point that more in-depth quantitative and qualitative data would enhance the interpretation of rural $v$. urban differences in employment, and encourage researchers to collect such data in future studies. Separate consideration of part-time $v$. full-time work would provide a more detailed understanding of the work status of persons with schizophrenia. As we indicate in the discussion, we believe that the greater flexibility of work in rural areas (i.e., allowing for part-time and full-time work depending on the individual's condition) may be an important factor in the higher rates of employment in rural areas. Comparisons of work satisfaction could also be useful, but such comparisons would require careful development of measures of work satisfaction that can be meaningfully compared for people with schizophrenia across these settings; to our knowledge, such measures are not yet available.

As regards collapsing all psychotic illnesses under the 'schizophrenia' rubric when assessing work status: in our study $90 \%(86 / 96)$ of urban residents with a psychotic illness and 